\title{
Advances in Smart Technologies for Structural Health Monitoring of Cable-stayed Bridges
}

\author{
Duc-Duy $\mathrm{Ho}^{1}$, Thanh-Cao $\mathrm{Le}^{2}$ \\ ${ }^{I}$ Faculty of Civil Engineering, Ho Chi Minh City University of Technology, VNU - HCM, Vietnam \\ ${ }^{2}$ Faculty of Civil Engineering, Nha Trang University, Vietnam \\ *Corresponding author: hoducduy@hcmut.edu.vn
}

\begin{abstract}
This study deals with the general problem of developing smart technologies for vibration and impedance-based structural health monitoring (SHM) of cable-stayed bridges. The following approaches are implemented to achieve the objective. Firstly, vibration- and impedance-based SHM methods suitable for cablestayed bridge are briefly outlined. Secondly, smart sensors are designed for vibration- and impedance-based SHM. Thirdly, the practicality of the smart sensor system is evaluated on a real cable-stayed bridge, Hwamyung Bridge in Korea. The system's performance is experimentally analyzed under various cable forces and weather conditions. Finally, the experimental modal parameters are identified by numerical modal analyses of the target bridge. Also, its structural parameters are estimated from the vibration-based structural identification using experimental modal parameters.
\end{abstract}

Keywords_-structural health monitoring; vibration; impedance; smart sensor; structural identification; cable-stayed bridge.

\section{INTRODUCTION}

$\mathrm{R}$ ecent tragic collapses of bridges and buildings have awoken the public on the need of structural health monitoring (SHM) that can play an important role in the safety and service life of civil infrastructure. Despite the efforts, the occurrence of damage in those structures is tended to be inevitable since they are subjected to extreme loading and environmental conditions that did not considered in design process. One of the promising ways to guarantee the structural safety and integrity is to enact SHM in a regular periodic manner and to detect critical damage in its early stage. Additionally, the time and cost associated with appropriate maintenance and repair should be also well managed to produce efficient outputs. In order to secure the structural integrity, many smart technologies have been developed [1][2].

During the last decades, the interest on the safety assessment of cable-stayed bridges has been increasing [3]. For a cable-stayed bridge, critical damage may be occurred in main structural components such as deck, cable, and pylon by resulting in stiffness-loss, crack growth, concrete degradation,... Critical damage in cable-anchorage subsystem may include cable force loss, anchorage damage and anchorage force loss. Eventually these damages may result in local and global failure of the bridge system. To avoid the above-mentioned situations, therefore, the cable-stayed bridge must be secured by a suitable SHM system that identifies damage occurrence and assesses the location and severity of damage on timely manner.

Moreover, many researchers have developed smart wireless sensors based on a variety of sensor platforms
[3-8]. By adopting those smart sensors for SHM in large structures, the costs are greatly reduced and the data processing and information management will be very effective by ways of sensing and on-board computation, wireless transmission, and green energy harvesting. However, the previous works have been mainly focused on implementing single-scale wireless sensor nodes for SHM on lab-scale structures. There have been a few fullscale implementations of wireless sensors for bridge monitoring so far.

In this study, smart technologies for vibration- and impedance-based SHM of cable-stayed bridges are presented. Firstly, vibration- and impedance-based SHM methods are briefly outlined. Secondly, the vibration and impedance smart sensors are described on the design of hardware components and embedded software. In this approach, a solar-powered energy harvesting is implemented for autonomous operation of the smart sensors. Finally, the feasibility of the smart sensor system is evaluated on Hwamyung cable-stayed bridge, in Korea. Successful level of wireless communication and solar-power supply for smart sensors are verified. Vibration and impedance responses measured from the target bridge which experiences various weather conditions are examined for the robust long-term monitoring capability of the smart sensor system. The bridge's structural parameters are also estimated from the vibration-based structural identification using experimental modal parameters.

\section{VIBRATION- AND IMPEDANCE-BASED SHM METHODS FOR CABLE-STAYED BRIDGE}

\section{A. Vibration-based SHM methods}

Vibration-based SHM methods utilize various dynamic features extracted from measured vibration signals. Vibration-based SHM is performed in four steps: (1) to measure vibration signals for distributed locations of sensors; (2) to extract vibration features (i.e., power 
spectral density, natural frequency and mode shape) for entire structure by using modal identification methods such as frequency domain decomposition (FDD) method or stochastic subspace identification (SSI) method [9]; (3) to identify damage occurrence in entire structure by performing change in natural frequency, correlation coefficient of power spectral densities [2]; and (4) to estimate the location and severity of damage, for example, the change in cable force [10]. In this sutdy, three common methods are selected as follows:

Firstly, the relative change in natural frequency is selected for global damage monitoring since the natural frequency is a global property of structure. The relative change in the $i^{\text {th }}$ natural frequency before and after the occurrence of structural damage is determined as

$$
\frac{\delta f_{i}}{f_{i}}=\frac{f_{i}^{*}-f_{i}}{f_{i}} \times 100 \%
$$

where $f_{i}, f_{i}^{*}$ are the $i^{t h}$ natural frequency before and after damage, respectively.

Secondly, the correlation coefficient (CC) of power spectral densities (PSDs) obtained before and after the occurrence of damage is calculated by the following equation [2]

$$
\rho_{x y}=\frac{E\left[S_{x x}(f) S_{y y}(f)\right]-E\left[S_{x x}(f)\right] E\left[S_{y y}(f)\right]}{\sigma_{S_{x x}} \sigma_{S_{y y}}}
$$

where $E[\bullet]$ is the expectation operator; $S_{x x}(f)$ and $S_{y y}(f)$ are the PSDs of two time signals before and after damage, respectively; and $\sigma_{S_{x x}}, \quad \sigma_{S_{y y}}$ are the corresponding standard deviations of PSDs, respectively.

Thirdly, based on the concept of the method proposed by Zui et al. [10], the following practical formula using multiple modes is used for estimation of cable force.

$$
T=\frac{1}{N M} \sum_{n=1}^{N M} T_{n}
$$

where $T$ is the average tension force; $N M$ is the number of vibration mode; and $T_{n}$ is the tension force using the $n^{\text {th }}$ mode and is determined as follow [10]: If $\xi<200$ then

$$
T_{n}=\frac{4 m}{n^{2}}\left(f_{n} L\right)^{2}\left[1-2.2 n \frac{C}{f_{n}}-0.55 n\left(\frac{C}{f_{n}}\right)^{2}\right]
$$

If $\xi \geq 200$ then

$$
T_{n}=\frac{4 m}{n^{2}}\left(f_{n} L\right)^{2}\left[1-2.2 n \frac{C}{f_{n}}\right]
$$

where $\xi$ is the parameter determined from cable properties and design conditions, $\xi=\sqrt{(T / E I)} \times L ; E I$ is the flexural rigidity of cable; $L$ is the span length of cable; $m$ is the mass of cable per unit length; $f_{n}$ is the natural frequency corresponding to the $n^{\text {th }}$ mode; and $C=\sqrt{\left(E I / m L^{4}\right)}$.

B. Modal-sensitivity structural identification method

Stubbs and Kim (1996) proposed a system identification method to identify a realistic theoretical model of a structure [11]. Then, Ho et al. (2012) modified the method for multi-phase system identification and evaluated its feasibility for a prestressed concrete girder [12]. Suppose $p_{j}^{*}$ is an unknown parameter of the $j^{\text {th }}$ member of a structure for which $M$ eigenvalues are known. Also, suppose $p_{j}$ is a known parameter of the $j^{\text {th }}$ member of a finite element (FE) model for which the corresponding set of $M$ eigenvalues are known. Then, relative to the FE model, the fractional structural parameter change of the $j^{\text {th }}$ member, $\alpha_{j} \geq-1$, and the structural parameters are related according to the following equation:

$$
p_{j}^{*}=p_{j}\left(1+\alpha_{j}\right)
$$

The dimensionless sensitivity, $S_{i j}$, of the $i^{\text {th }}$ eigenvalue $\omega_{i}^{2}$ with respect to the $j^{\text {th }}$ structural parameter $p_{j}$ is defined as follows:

$$
S_{i j}=\frac{\delta \omega_{i}^{2}}{\delta p_{j}} \frac{p_{j}}{\omega_{i}^{2}}
$$

where $\delta p_{j}$ is the first order perturbation of $p_{j}$ which produces the variation in eigenvalue $\delta \omega_{i}^{2}$. The fractional structural parameter change of $N E$ members may be obtained using the following equation:

$$
\{\alpha\}=[S]^{-1}\{Z\}
$$

where $\{\alpha\}$ is a $N E \times 1$ matrix containing the fractional changes in structural parameters between the FE model and the target structure; $\{Z\}$ is a $M \times 1$ matrix containing the fractional changes in eigenvalues between two systems; and $[S]$ is a $M \times N E$ sensitivity matrix. To identify the completeness of the FE model update, the convergence criterion between the measured and analytical eigenvalues is set as follows:

$$
\left|Z_{i}\right|=\left|\frac{\omega_{i, m}^{2}-\omega_{i, a}^{2}}{\omega_{i, a}^{2}}\right| \leq \text { tolerance }
$$

where $\omega_{i, m}^{2}$ and $\omega_{i, a}^{2}$ are the $i^{t h}$ eigenvalues of the measured target structure and the analytical model, respectively.

\section{Impedance-based SHM method}

Mechanical impedance of host structure is a function of mass, damping and stiffness. When a structure is damaged, its mechanical impedance would be changed. Any changes in dynamic characteristics of host structure, hence, can be represented by the change in impedance signatures [2]. The impedance-based SHM is performed in four steps: (1) to measure impedance signal from PZT sensor bonded to local critical member; (2) to extract impedance features such as real part, imaginary part, phase and magnitude; (3) to monitor the damage occurrence in local member by using statistical index based methods such as root mean square deviation (RMSD) of impedance signatures; and (4) to identify the pattern of damage. The RMSD is calculated from impedance signatures measured before and after damage as [2] 


$$
\operatorname{RMSD}\left(Z, Z^{*}\right)=\sqrt{\frac{\sum_{i=1}^{N}\left[Z^{*}\left(\omega_{i}\right)-Z\left(\omega_{i}\right)\right]^{2}}{\sum_{i=1}^{N}\left[Z\left(\omega_{i}\right)\right]^{2}}}
$$

where $Z\left(\omega_{i}\right)$ and $Z^{*}\left(\omega_{i}\right)$ are the impedances measured before and after damage for the $i^{\text {th }}$ frequency, respectively; and $N$ denotes the number of frequency points in the sweep.

\section{VIBRATION AND IMPEDANCE SMART SENSORS}

\section{A. Hardware design}

For the vibration- and impedance-based SHM, vibration and impedance sensor nodes on Imote2 platform were designed as schematized in Fig.1. The high-performance sensor platform, Imote2, provided by Memsic Co. was selected to control the operation of the sensor node. For vibration monitoring, SHM-A, SHMAS and SHM-H sensor boards were selected. The SHMA and SHM-H sensor boards were developed for acceleration measurement by University of Illinois at Urbana-Champaign (UIUC) [7, 13, 14]. The SHM-AS sensor board was modified from SHM-A sensor board in order to measure PZT's dynamic strain signal [15]. For impedance monitoring, an Imote2-platformed impedance sensor board (SSeL-I) developed by Pukyong National University (PKNU) [8] was selected. As also shown in Fig.1, the solar-powered energy harvesting is implemented by employing solar panel and rechargeable battery. Figure 2 shows the prototype of the multi-scale sensor node which consists of four layers as 1) X-bow battery board, 2) Imote2 sensor platform, 3) SHM-H board or SHM-A (AS) board, and 4) SSeL-I board.

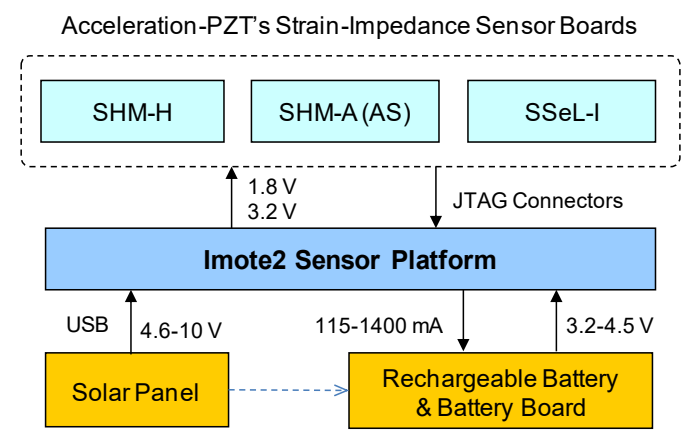

Figure 1. Schematic of smart sensors

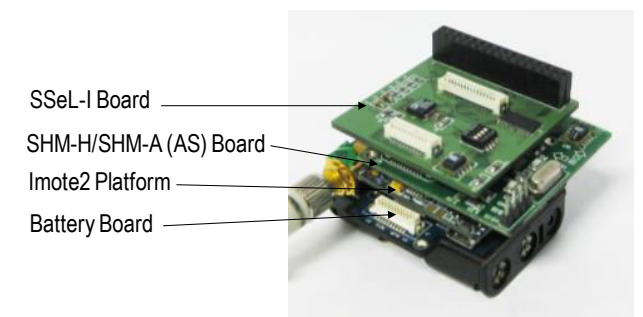

Figure 2. Prototype of smart sensors on Imote2 platform

\section{B. Software design}

\section{1) Vibration-based SHM software}

As schematized in Fig. 3, device drivers of vibrationbased SHM are programmed for the Imote2/SHMA(AS)/SHM-H according to UIUC ISHMP Service
Toolsuite and PKNU SSeL SHM Tools [15]. The sensor nodes are embedded with the following components: RemoteSensing for synchronized vibration measurements, AutoMonitor for autonomous operation and ChargerControl for solar power harvesting. After finishing vibration measurements, all the measured data from leaf nodes are transmitted to a gateway node. Then the data is processed to feature extraction and damage detection from SSeL SHM tools. The SSeL SHM tools include a device driver for ADC and mathematical functions for damage monitoring such as PSD, CC of PSDs. Also, the FDD method and SSI method are embedded into the system to extract modal parameters such as natural frequencies and mode shapes.

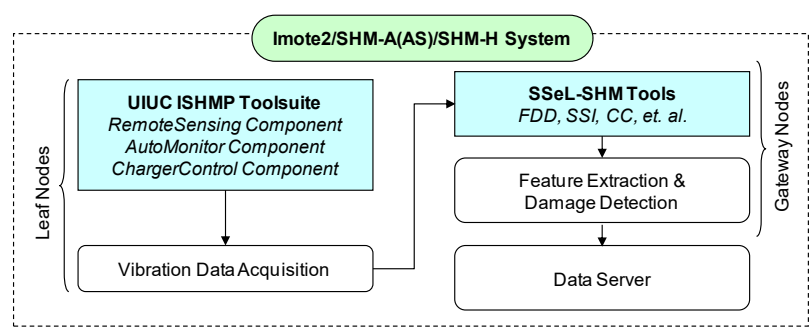

Figure 3. Schematic of vibration-based SHM software

\section{2) Impedance-based SHM software}

As schematized in Fig. 4, device drivers of impedancebased SHM are programmed for the Imote2/SSeL-I according to UIUC ISHMP Service Toolsuite and PKNU SSeL SHM Tools [15]. The sensor nodes are embedded with the following components: Impedance for impedance measurements, ImpAutoMonitor for autonomous operation and ChargerControl for solar power harvesting. After finishing impedance measurements, all the measured data from leaf nodes are transmitted to a gateway node. Then the data is processed to feature extraction and damage detection from SSeL SHM tools. The SSeL SHM Tools include a device driver for impedance measurement and mathematical functions for damage monitoring such as RMSD of impedance signatures.

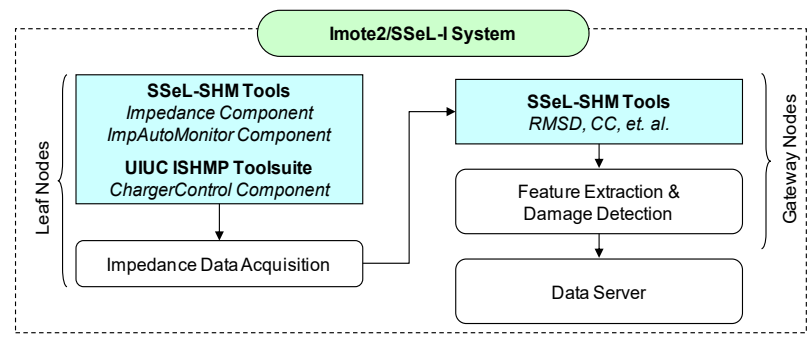

Figure 4. Schematic of impedance-based SHM software 


\section{FIELD APPLICATION OF SMART SENSOR SYSTEM ON HWAMYUNG CABLE-STAYED BRIDGE}

A. Experiments on Hwamyung Bridge

1) Description of Hwamyung Bridge

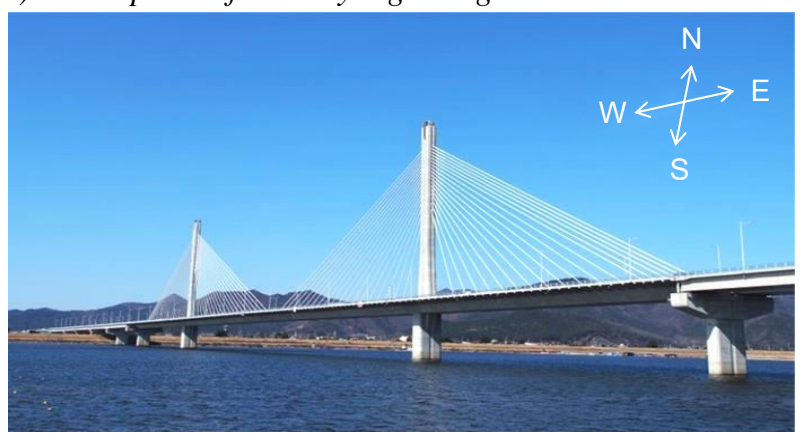

Figure 5. Hwamyung cable-stayed bridge

Hwamyung Bridge is a cable-stayed bridge crossing Nakdong river between Busan and Gimhae, Korea, as shown in Fig. 5. It is the longest cable-stayed bridge with prestressed concrete box girder in Korea as so far. The bridge consists of three spans including a 270 -m central main span between two pylons and two 115-m side spans connecting east and west approaches. The clearance of the deck is $14.7 \mathrm{~m}$ from the water level. The height of two pylons is $65-\mathrm{m}$ from deck level. The box girder supported by single plane stayed-cable is $27.8 \mathrm{~m}$ in width and $4 \mathrm{~m}$ in height. The bridge has total 72 cables, positioning 18 cables at one side of pylon.

\section{2) Field deployment of smart sensor system}

In order to monitor the responses of Hwamyung cablestayed bridge, two hardware configurations of Imote2based smart sensor nodes which are gateway node and leaf node are designed. As schematized in Fig. 6, a gateway node consists of an Imote 2 platform with 2.4 $\mathrm{GHz}$ antenna, an IBB2400 interface board connected to the PC via USB cable. A leaf node consists of an Imote2 platform with $2.4 \mathrm{GHz}$ antenna, a sensor board (e.g., SHM-AS, SHM-H, SSeL-I), X-bow battery board powered by $\mathrm{D}$-cell batteries or by Powerizer Li-ion polymer rechargeable battery with or without solar panel.

As shown in Fig. 6, total sixteen (16) smart sensor nodes (Imote2/SHM-AS/SHM-H) including fifteen leaf nodes and one gateway node (i.e., gateway vibration) were installed for vibration measurement of the bridge. Four Imote2/SHM-H sensors were placed on four cables (i.e., C1, C2, C4, and C5). Six Imote2/SHM-H sensors were placed at five locations of the deck and at the top of the west pylon (i.e., D1, D2, D3, D4, D5, and P1). As also shown in Fig. 6, five Imote2/SHM-AS sensors were placed on five selected cables (i.e., C1 C5). For each sensor board (i.e., SHM-H or SHM-AS), three axes accelerations were measured. A spared channel in SHMAS sensor board was used for measuring dynamic strain in cable. Five PZT patches were bonded on aluminum tubes covering the five selected cables to measure dynamic strain signals. These PZT patches were connected to external channels of SHM-AS sensor boards. In summary, total 45 channels were used for acceleration measurement and 5 channels were used for dynamic strain measurement in Hwamyung Bridge. The vibration signals were measured in duration 600 seconds with sampling rate $25 \mathrm{~Hz}$.

As also noted in Fig. 6, total six (6) smart sensor nodes (Imote2/SSeL-I) including one gateway node (i.e., gateway impedance) were installed for impedance measurement of cable system. Five PZT patches connected to the SSeL-I sensor boards (leaf nodes) were bonded on the five selected cable anchorage zones (i.e., $\mathrm{C} 1 \sim \mathrm{C} 5)$. The impedance signatures were measured in frequency range of $10 \mathrm{kHz} 100 \mathrm{kHz}$ with 500 intervals of sweeping frequency.

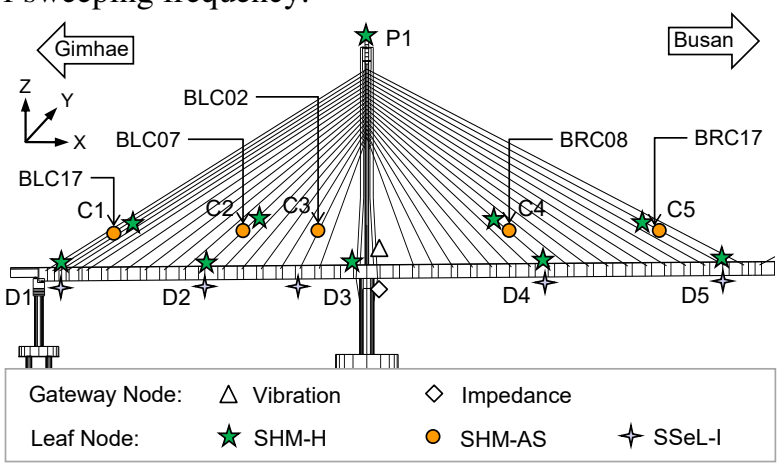

Figure 6. Field sensor layout

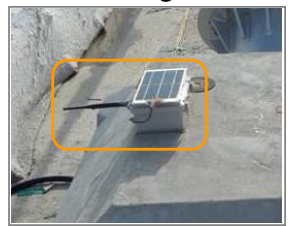

(a) Deck node

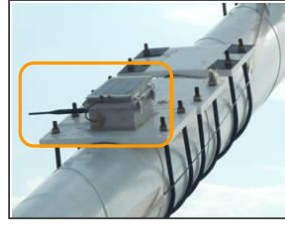

(c) Cable node

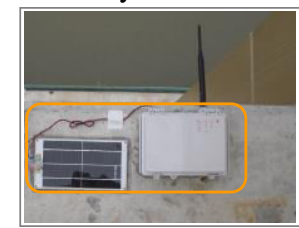

(b) Top pylon node

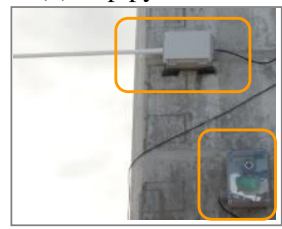

(d) Gateway node
Figure 7. Field deployment of smart sensor nodes

All sensor nodes and base station are placed in plastic boxes which have waterproof rubber gaskets, as shown in Fig. 7, to prevent them from sun-heating, absorbent, and other damage caused by harsh environmental condition such as rain, wind, and dust at the field site. The base station includes a PC, two gateway nodes (one for vibration measurement and another for impedance measurement) and a commercial broadband (T-login) modem to connect the PC to internet. Note that the two gateway nodes were set up with different USB ports and radio channels to avoid the interference in transmitting commands to and receiving data from leaf nodes. An external antenna was connected to Imote2 platform of each sensor node. Solar panels were mounted on the sensor boxes to harvest the solar energy for recharging the Li-ion polymer batteries embedded to the sensor boards. A webcam was installed on the west pylon to observe the bridge's condition in real-time.

\section{B. Long-term monitoring performance of smart sensors 1) Test history}

The Hwamyung Bridge was monitored by the smart sensor system for three months (from $21^{\text {st }}$ June to $20^{\text {th }}$ September, 2011). The bridge was instrumented on two separate periods. In the first period (from $21^{\text {st }}$ June to 
$14^{\text {th }}$ July, 2011), accelerations were only measured by the Imote2/SHM-AS and Imote2/SHM-H. In the second period (from $7^{\text {th }}$ August to $20^{\text {th }}$ September, 2011), accelerations, PZT's dynamic strains and impedances were measured by the Imote2/SHM-AS, Imote2/SHM-H, and Imote2/SSeL-I.

2) Wireless communication and power consumption

Responses of the bridge were measured by smart sensor system with AutoMonitor two-hour interval under ambient vibration condition. During the monitoring period, working status of the sensor system was evaluated. Figure 8 shows performance evaluation of wireless communication from $25^{\text {th }}$ June to $14^{\text {th }}$ July, 2011. As indicated in the figure, the characters ' $H$ ' and 'A' denote the Imote2/SHM-H and Imote2/SHM-AS, respectively. The sensor nodes were well responsive (i.e., 90\% successful level), except the sensor nodes distanced far from base station (i.e., sensors D1, C1, C5). Figure 9 shows performance evaluation of power consumption for three sensor nodes (i.e., sensors P1, D2, C4) during twenty days (i.e., $25^{\text {th }}$ June $14^{\text {th }}$ July, 2011) due to the change in weather conditions. The voltage of sensor node integrated with solar panel and rechargeable battery (i.e., sensor P1) remained around $4.1 \mathrm{~V}$. Meanwhile, the voltages of sensor nodes integrated with only rechargeable battery (i.e., sensor D2) or D-cell batteries (i.e., sensor C4) were decreased day after day. This proves that the charging process of solar-powered sensor nodes was stably working.

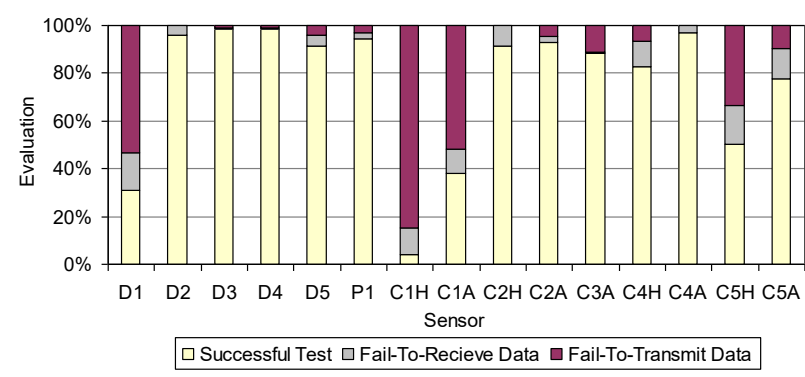

Figure 8. Performance evaluation of wireless communication

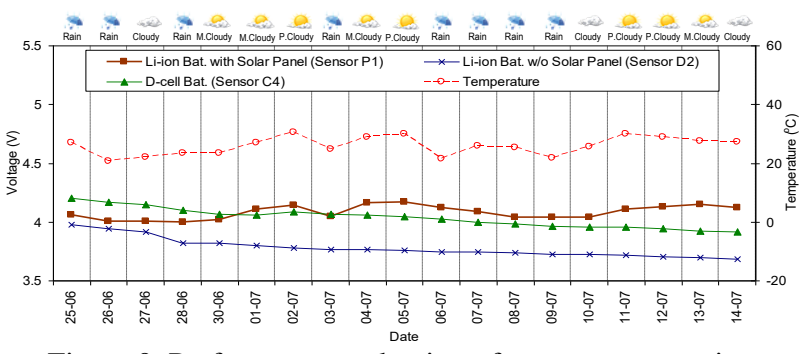

Figure 9. Performance evaluation of power consumption

\section{3) Vibration monitoring under typhoon condition}

In this section, vibration responses of the bridge measured and analyzed due to the change in weather conditions are described. On $25^{\text {th }}$ and $26^{\text {th }}$ June, 2011, a typhoon named Meari passed though the Korean peninsula and directly affected the site of Hwamyung Bridge. Figures 10 12 show acceleration responses and PSDs measured from top pylon P1, deck D2 and cable C4 under normal condition and typhoon Meari, respectively. The natural frequencies indicated in the figures were determined by reading the peak frequencies in PSD functions.
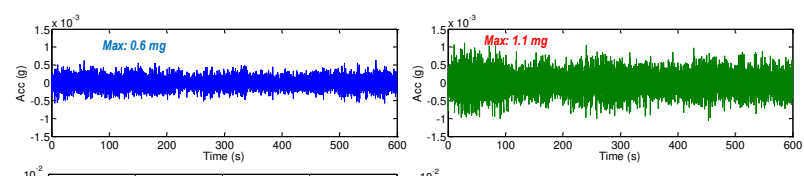

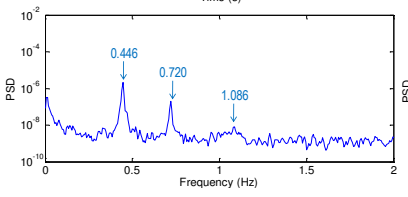

(a) Normal condition

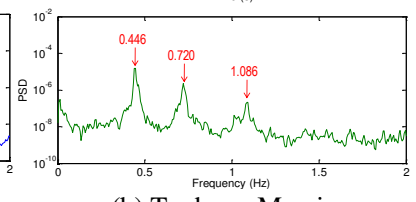

(b) Typhoon Meari
Figure 10. Acceleration responses and PSDs of top pylon P1
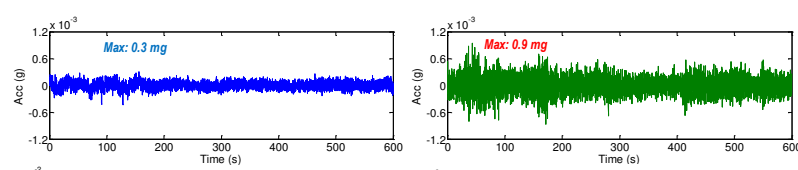

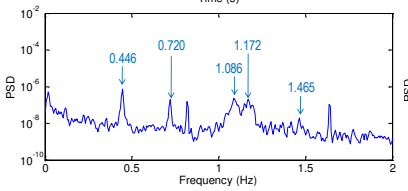

(a) Normal condition

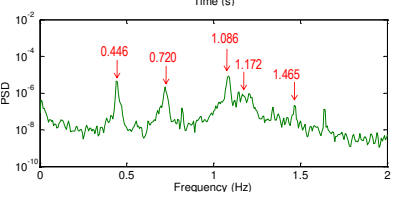

(b) Typhoon Meari
Figure 11. Acceleration responses and PSDs of deck D2

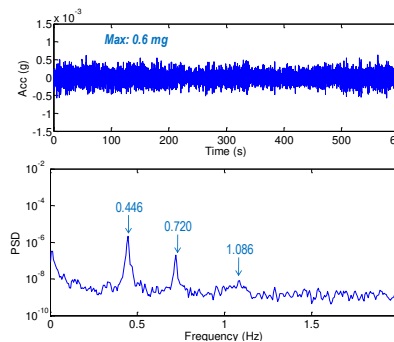

(a) Normal condition
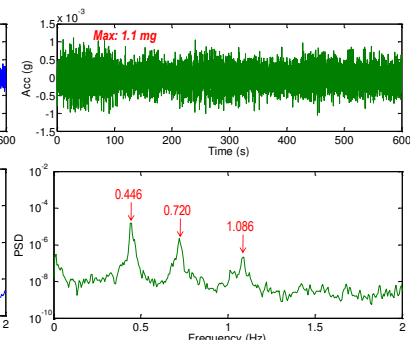

(b) Typhoon Meari
Figure 12. Acceleration responses and PSDs of cable C4

During the typhoon period, the vibration of the bridge almost increased as much as 2 times for top pylon P1 (i.e., $0.6 \mathrm{mg}$ to $1.1 \mathrm{mg}$ ), 3 times for deck D2 (i.e., $0.3 \mathrm{mg}$ to $0.9 \mathrm{mg}$ ), and 2 times for cable C4 (i.e., $14 \mathrm{mg}$ to 29 $\mathrm{mg}$ ). The natural frequencies of top pylon P1 and deck D2 were remained unchanged during the typhoon pass, as shown in Figs. 10 and 11. Meanwhile, the natural frequencies of cable $\mathrm{C} 4$ were reduced about $0.2 \%$ for mode 2 and $0.3 \%$ for mode 3, as shown in Fig. 12. Note that there are unexpected periodical peaks (i.e., $0.8 \mathrm{~Hz}$, $1.6 \mathrm{~Hz}$ ) in frequency domain as shown in Fig. 11. Those indications are unexpected from numerical modal analysis, which is described in the later part. It has been reported that these noisy peaks can be caused by power supply issue of SHM-H sensor board [13]. Further studies should be made to resolve the problem related to the performance of the SHM-H sensor board.

4) Long-term SHM under weather change

The performance of the smart sensor system was evaluated for vibration- and impedance-based monitoring under various weather conditions. The cable C3 was selected as a target structure. During five-day experiment $\left(13^{\text {th }}\right.$ to $17^{\text {th }}$ August, 2011), vibration and impedance signals were recorded by the sensor nodes placed on the cable C3, as indicated in Fig. 6. Figure 13 shows acceleration responses and PZT's dynamic strain responses. It is observed from the figure that when the temperature slightly goes up (i.e., $26^{\circ} \mathrm{C} \sim 30^{\circ} \mathrm{C}$ ), the PSDs shift to the left side indicating the cable's natural 
frequency reduction.
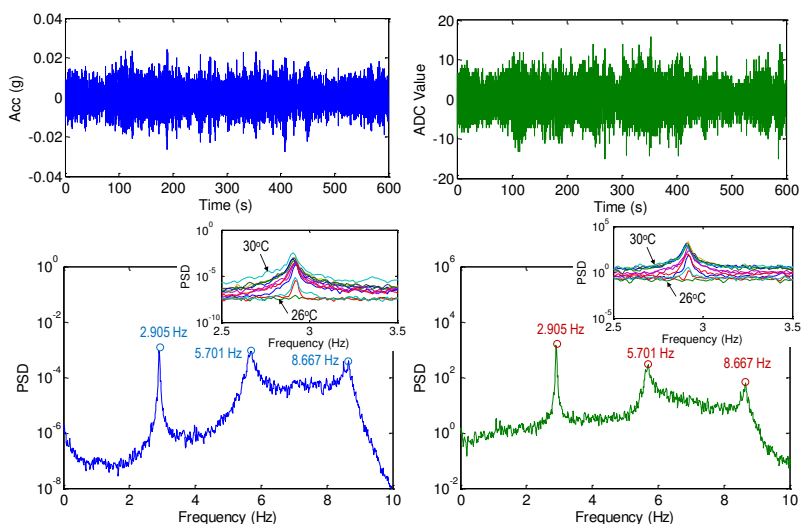

Figure 13. Vibration responses on cable $\mathrm{C} 3$

Figure 14 shows the relative changes in the first natural frequency calculated by Eq. (1) versus the temperature change. The natural frequency decrease as the temperature goes up, and vice versa. Figure 15 shows the $\mathrm{CC}$ of PSDs calculated by Eq. (2) versus the temperature change during the five-day monitoring. The CC of PSDs consistently changes due to the change in weather conditions. The monitoring results using acceleration and PZT's dynamic strain responses show good agreement. This proves that the PZT's dynamic strain can be used as vibration feature for SHM.

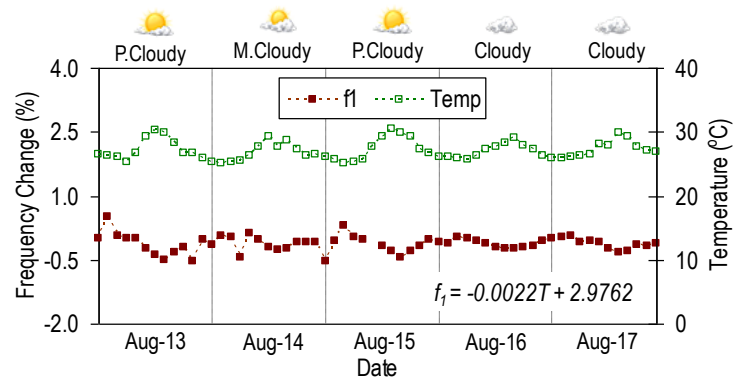

(a) Acceleration

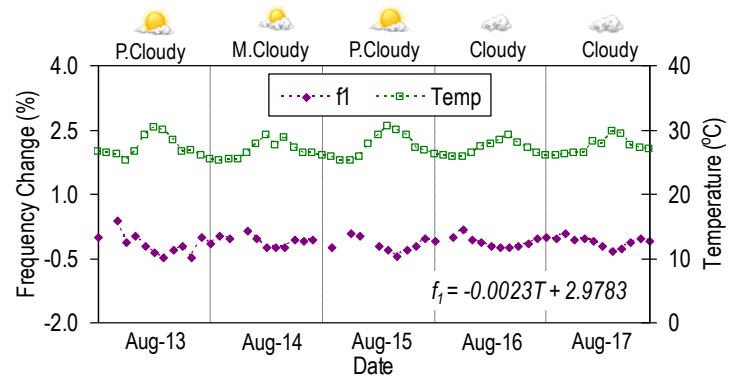

(b) PZT's Dynamic Strain

Figure 14. Relative changes in natural frequency versus various temperatures on cable $\mathrm{C} 3$

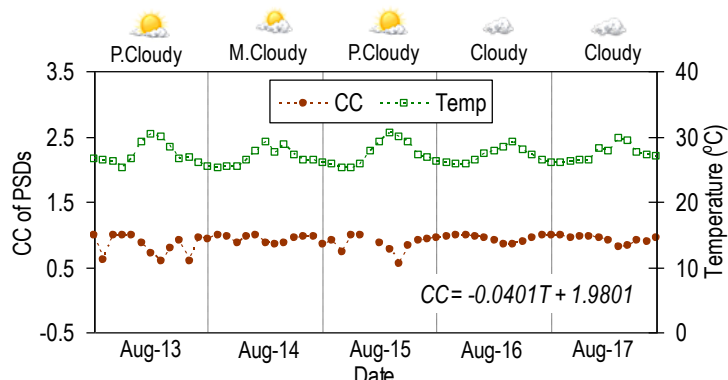

(a) Acceleration

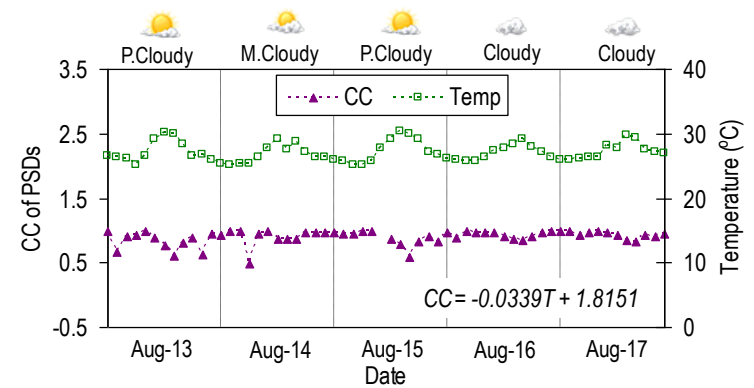

(b) PZT's Dynamic Strain

Figure 15. CCs of PSDs versus various temperatures on cable C3

At the same monitoring period, impedance signatures were measured from the PZT sensor on anchorage of cable C3, as shown in Fig. 16. The impedances are sensitive to the temperature change. As shown in the figure, when the temperature slightly increases from $26^{\circ} \mathrm{C}$ to $30^{\circ} \mathrm{C}$, the real impedance signatures shift to the right side indicating the cable's impedance frequency increment. In order to evaluate this effect, the RMSD of impedance signatures were computed by Eq. (10). From the impedance monitoring results shown in Fig. 17, it is observed that the RMSD of impedance tends to increase as the temperature increases, and vice versa.

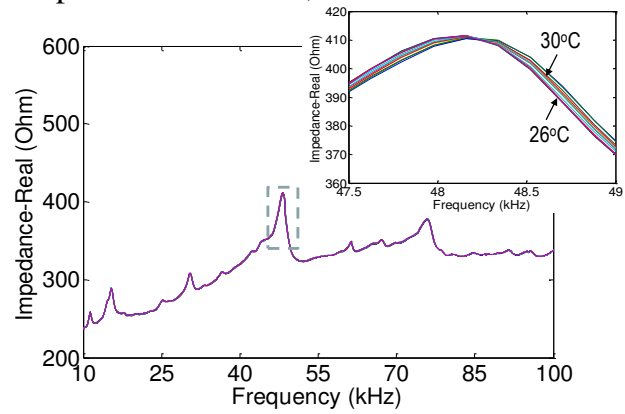

Figure 16. Impedance responses on cable C3

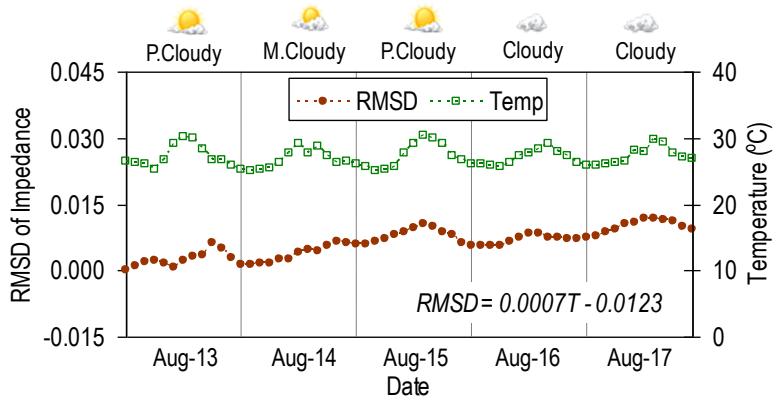

Figure 17. RMSD impedance signatures versus various temperatures on cable $\mathrm{C} 3$

\section{Cable force monitoring}

For cable-stayed bridge, cable force is one of the important targets needed to be monitored for the safety and service life of the bridge. In order to estimate cable force, cable's natural frequencies should be accurately measured. The SSI method [9] was employed to extract the cable's natural frequencies. The SSI method gives more accurate natural frequency than reading the peak frequency in PSD function. Frequency ranges are set up based on theoretical natural frequencies which are calculated by string theory. From acceleration signals measured by Imote2/SHM-AS sensor nodes on the five 
cables $\mathrm{C} 1 \sim \mathrm{C} 5$, the first three natural frequencies were measured at temperature $27.9^{\circ} \mathrm{C}$, as listed in Table 1. For more feasible comparison, cable forces of the five cables C1 C5 were estimated by using the frequency-based cable force model stated in Eqs. (3) (5). In comparison with designed values, Fig. 18 shows the estimated cable forces for the cables $\mathrm{C} 1 \sim \mathrm{C} 5$. The results show good agreement with small differences, as listed in Table 1. The differences varied within $0.4 \% \sim 10.3 \%$ depending on the cables. The estimated forces which were calculated from the experimental data reflect the real value of cable forces more accurately than the designed forces which were determined from the design conditions. Note that the estimated forces depend on the number of vibration modes used for the frequency-based cable force model.

Table 1. Estimated forces of cables C1 C5

Cable Designed force Experimental freqs. Estimated force

\begin{tabular}{|c|c|c|c|c|c|}
\hline \multirow{2}{*}{\multicolumn{2}{|c|}{$(\mathrm{kN})$}} & \multicolumn{3}{|c|}{$(\mathrm{Hz})$} & \multirow[t]{2}{*}{$(\mathrm{kN})$} \\
\hline & & Mode 1 & Mode 2 & Mode 3 & \\
\hline $\mathrm{C} 1$ & 7456.3 & 1.139 & 2.270 & 3.404 & 7857.8 \\
\hline $\mathrm{C} 2$ & 4728.4 & 1.741 & 3.452 & 5.143 & 4681.1 \\
\hline $\mathrm{C} 3$ & 4828.0 & 2.912 & 5.668 & 8.702 & $4332.3 \quad(10.3)$ \\
\hline $\mathrm{C} 4$ & 4278.9 & 1.559 & 3.107 & 4.619 & $4386.8 \quad(2.5)$ \\
\hline $\mathrm{C} 5$ & 9612.4 & 1.053 & 2.104 & 3.155 & $9652.1 \quad(0.4)$ \\
\hline
\end{tabular}

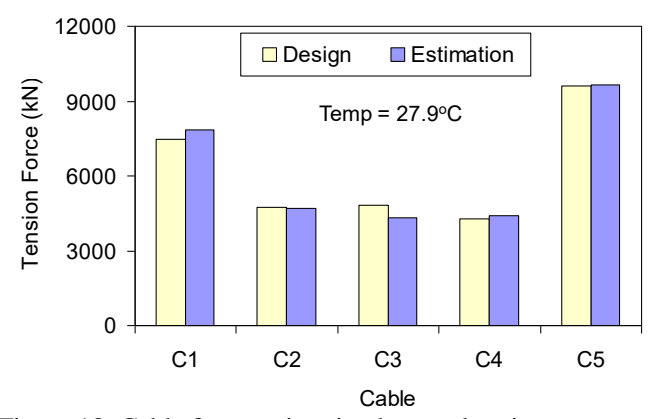

Figure 18. Cable force estimation by acceleration responses

The use of PZT's dynamic strain to estimate cable force is also evaluated. Table 2 shows the experimental natural frequencies of cable $\mathrm{C} 3$ extracted from acceleration and PZT's dynamic strain responses on August $17^{\text {th }}$ with various temperatures. Cable forces were estimated by using the Eqs. (3) (5), as listed in Table 2 and also shown in Fig. 19. It is obvious that the cable forces estimated from the PZT's dynamic strains are well identical to those estimated from acceleration responses. The cable forces, generally, tend to decrease as the temperature increases, and vice versa.

Table 2. Experimental natural frequencies and cable force estimation from acceleration and PZT's dynamic strain responses for cable C3 versus temperature on August $17^{\text {th }}$

\begin{tabular}{cccccccc}
\hline \multirow{2}{*}{ Response } & \multicolumn{7}{c}{ Time (Temperature) } \\
\cline { 2 - 8 } & & $00: 14$ & $04: 15$ & $08: 16$ & $12: 17$ & $16: 19$ & $20: 20$ \\
& Mode 1 & $\left.25.99^{\circ} \mathrm{C}\right)$ & $\left(26.1^{\circ} \mathrm{C}\right)$ & $\left(26.4^{\circ} \mathrm{C}\right)$ & $\left(27.8^{\circ} \mathrm{C}\right)$ & $\left(29.3^{\circ} \mathrm{C}\right)$ & $\left(27.1^{\circ} \mathrm{C}\right)$ \\
\hline \multirow{2}{*}{ Acc-Freq. (Hz) } & Mode 2 & 5.698 & 5.724 & 2.918 & 2.913 & 2.912 & 2.915 \\
& Mode 3 & 8.610 & 8.623 & 8.672 & 8.647 & 8.634 & - \\
\hline MZde 1 & 2.920 & 2.922 & 2.919 & 2.913 & 2.912 & 2.919 \\
PZT-Freq. (Hz) Mode 2 & 5.677 & 5.715 & 5.701 & 5.699 & 5.683 & 5.686 \\
& Mode 3 & - & - & - & 8.649 & 8.652 & - \\
\hline Acc-Force (kN) & 4323.8 & 4343.9 & 4342.2 & 4323.1 & 4317.1 & 4319.2 \\
PZT-Force (kN) & 4323.1 & 4355.3 & 4340.1 & 4331.3 & 4321.9 & 4328.2 \\
Difference (\%) & 0.02 & 0.26 & 0.05 & 0.19 & 0.11 & 0.21 \\
\hline
\end{tabular}

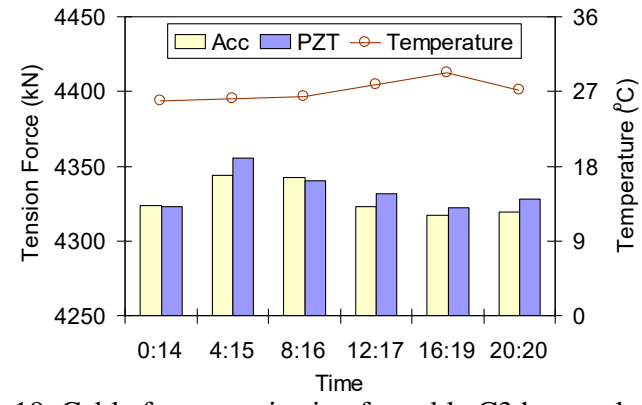

Figure 19. Cable force monitoring for cable C3 by acceleration and PZT's dynamic strain responses

\section{Experimental modal identification}

\section{1) Numerical modal analysis}

In order to analyze numerical modal parameters and to identify the corresponding experimental modal parameters of the test bridge, a FE model of Hwamyung Bridge was established using SAP2000 as shown in Fig. 20. Two pylons and main girder were modeled by frame elements with dimensions as same as bridge design drawing. Stayed-cables were modeled by cable elements with equivalent circular cross sections which have the same total areas with designed ones. By modeling as cable element, nonlinear stiffness of cable due to post tension force was taken into account. Material properties of girder and two pylons were defined as concrete with Young's modulus of $28.6 \mathrm{GPa}$, Poisson's ratio of 0.2 , and mass density of $2500 \mathrm{~kg} / \mathrm{m}^{3}$. Meanwhile, material properties of cables were defined as steel with Young's modulus of $195 \mathrm{GPa}$, Poisson's ratio of 0.3 , and mass density of $7850 \mathrm{~kg} / \mathrm{m}^{3}$. For the boundary conditions, two pylons and two girder ends were assigned by springs in three directions as shown in Fig. 20. The stiffness of support springs depend on the foundation conditions which beyond the scope of this study. Therefore, they were assumed as $k_{d-x}=10^{6} \mathrm{~N} / \mathrm{m}, k_{d-y}=5 \times 10^{7} \mathrm{~N} / \mathrm{m}, k_{d-z}=$ $10^{9} \mathrm{~N} / \mathrm{m}$ for deck supports and $k_{p-x}=10^{10} \mathrm{~N} / \mathrm{m}, k_{p-y}=10^{10}$ $\mathrm{N} / \mathrm{m}, \quad k_{p-z}=10^{10} \mathrm{~N} / \mathrm{m}$ for pylon supports. Modal parameters of the FE model were analyzed with consideration of p-delta effects of cable post tensions. The designed and the five estimated data of cable forces were assigned to the initial FE model.

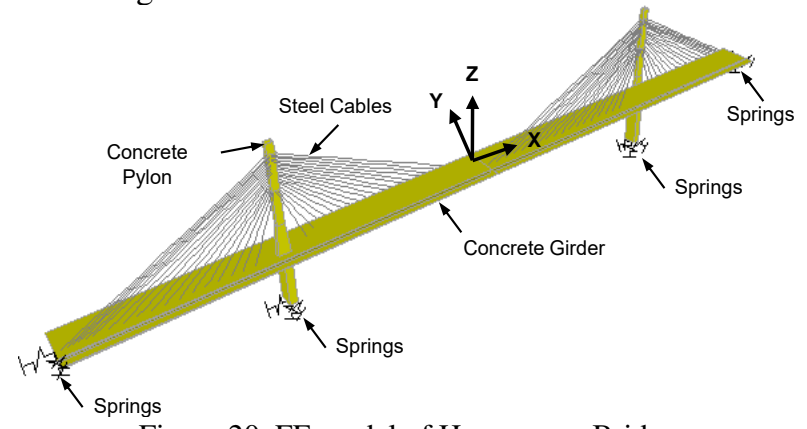

Figure 20. FE model of Hwamyung Bridge

\section{2) Experimental modal identification}

In order to extract experimental natural frequencies and mode shapes of deck and pylon, the SSI method [9] was performed. Figure 21 shows the stabilization chart obtained in the SSI process for vertical and transverse responses. The first six vertical bending modes (i.e., $\mathrm{V} 1 \sim \mathrm{V} 6)$ and three transverse bending modes (i.e., L1 L3) were extracted. The corresponding mode shapes 
and natural frequencies are shown in Fig. 22. As shown in the figure, the mode shapes of bridge were well extracted by the six Imote2/SHM-H sensor nodes on deck and pylon. Also, the numerical modal analyses show good agreement with experimental results. The differences of natural frequency range from $0.4 \%$ to $8.8 \%$. Those differences are moderate for the initial FE model based on the design parameters. Therefore, the FE model should be fine-tuned appropriately to represent the behaviors of the bridge.

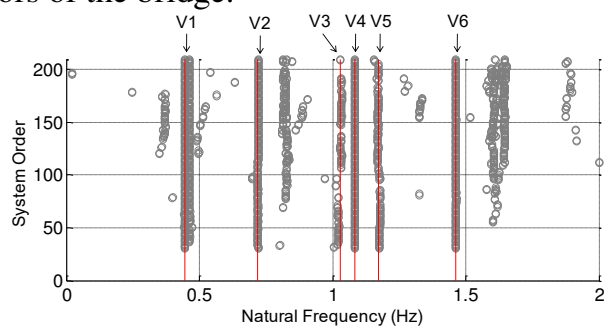

(a) Vertical modes
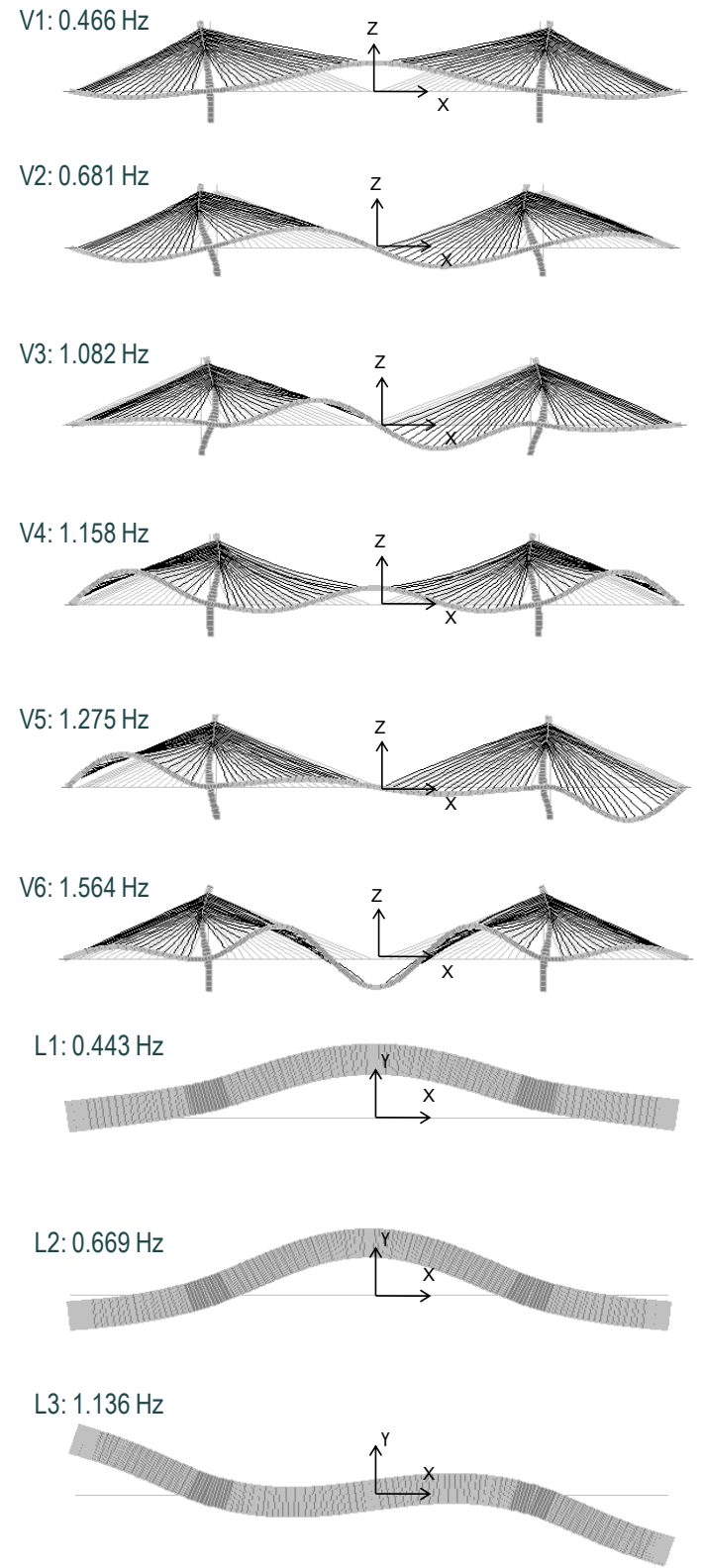

(a) Numerical mode shapes

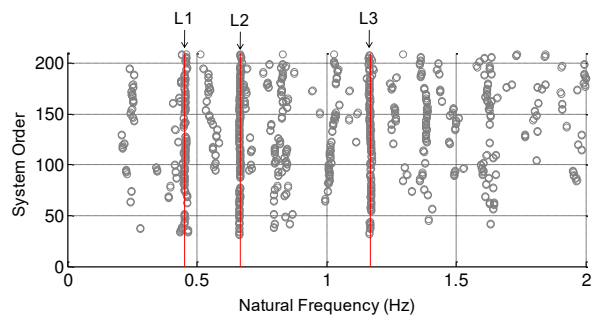

(b) Lateral modes

Figure 21. SSI method: stabilization charts

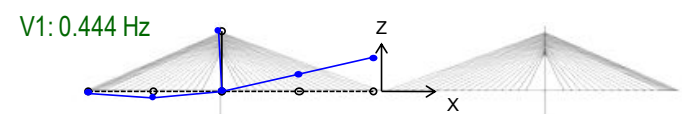

V2: $0.720 \mathrm{~Hz}$

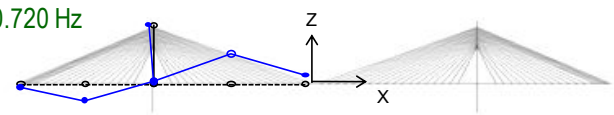

V3: $1.028 \mathrm{~Hz}$

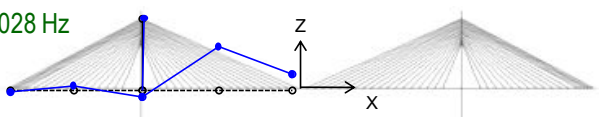

V4: $1.084 \mathrm{~Hz}$

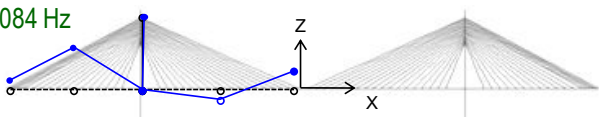

V5: $1.171 \mathrm{~Hz}$

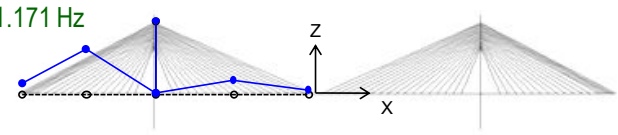

V6: $1.462 \mathrm{~Hz}$

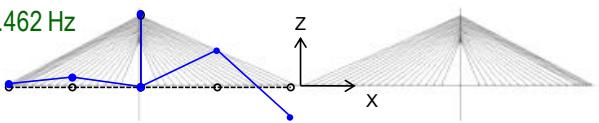

L1: $0.454 \mathrm{~Hz}$

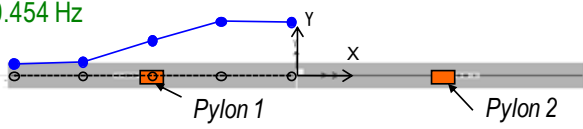

L2: $0.666 \mathrm{~Hz}$

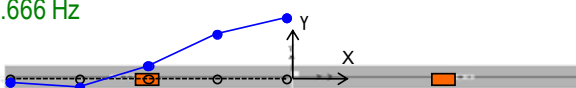

L3: $1.169 \mathrm{~Hz}$

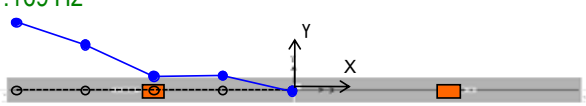

(b) Experimental mode shapes

Figure 22. Modal identification for deck and pylon 


\section{STRUCTURAL IDENTIFICATION OF HWAMYUNG CABLE-STAYED BRIDGE}

In order to perform the structural integrity assessment which is the last step of SHM, the modal sensitivitybased structural identification process, as described in section II, was performed to identify a baseline model of Hwamyung Bridge. Then, the identified baseline model can play a role of the reference structure to make diagnosis on the target bridge.

\section{A. Model-updating parameters}

Choosing appropriate structural parameters is an important step in the FE model-updating procedure. All parameters related to structural geometries, material properties, and boundary conditions can be potential choices for adjustment in the model-updating procedure. The model-updating parameters should be selected on the basis of the following two facts. Physically, the structural parameters which are uncertain in the model due to the lack of knowledge on structural properties should be selected. Also, the structural parameters which are relatively sensitive to vibration responses should be selected. For Hwamyung Bridge, nine potential groups of model-updating parameters were selected as follows:

$(E I)_{d} \quad$ : stiffness of deck

$(E I)_{u-p}$ : stiffness of upper-pylons

$(E I)_{l-p}:$ stiffness of lower-pylons

$(k)_{d-x} \quad$ : stiffness of X-direction deck support springs

$(k)_{d-y} \quad$ : stiffness of Y-direction deck support springs

$(k)_{d-z} \quad$ : stiffness of Z-direction deck support springs

$(k)_{p-x} \quad$ : stiffness of $\mathrm{X}$-direction pylon support springs

$(k)_{p-y} \quad$ : stiffness of Y-direction pylon support springs

$(k)_{p-z} \quad$ : stiffness of Z-direction pylon support springs

The model-updating parameters were divided as one group for deck, two group for pylons (i.e., one group for pylons located upper the deck level and another group for pylons located lower the deck level), and six groups for support springs. Then, the eigenvalue sensitivity analysis for the nine groups of model-updating parameters was carried out by Eq. (7), as listed in Table 3 and also shown in Fig. 23. The stiffness of deck and the stiffness of pylons were constrained within $10 \%$ since the initial values of these parameters were assumed as the design. Meanwhile, the stiffness of support springs was unconstrained due to the unknown foundation conditions.

Table 3. Eigenvalue sensitivities of model-updating parameters

\begin{tabular}{cccccccccc}
\hline \multirow{2}{*}{ Mode } & \multicolumn{7}{c}{ Eigenvalue sensitivity } \\
\cline { 2 - 9 } & $(\mathrm{EI})_{d}$ & $(\mathrm{E} I)_{u-p}$ & $(\mathrm{E} I)_{1-p}$ & $(\mathrm{k})_{d-x}$ & $(\mathrm{k})_{d-y}$ & $(\mathrm{k})_{d-z}$ & $(\mathrm{k})_{p-x}$ & $(\mathrm{k})_{p-y}$ & $(\mathrm{k})_{p-z}$ \\
\hline V1 & $3.9 \mathrm{E}-1$ & $3.8 \mathrm{E}-2$ & $7.6 \mathrm{E}-2$ & $4.9 \mathrm{E}-5$ & $2.1 \mathrm{E}-12$ & $1.1 \mathrm{E}-2$ & $3.7 \mathrm{E}-3$ & $3.6 \mathrm{E}-12$ & $5.4 \mathrm{E}-3$ \\
V2 & $4.0 \mathrm{E}-1$ & $9.3 \mathrm{E}-2$ & $3.3 \mathrm{E}-1$ & $1.3 \mathrm{E}-3$ & $3.4 \mathrm{E}-12$ & $8.0 \mathrm{E}-3$ & $7.8 \mathrm{E}-3$ & $4.7 \mathrm{E}-12$ & $6.5 \mathrm{E}-4$ \\
V3 & $4.0 \mathrm{E}-1$ & $6.7 \mathrm{E}-2$ & $3.2 \mathrm{E}-1$ & $9.1 \mathrm{E}-4$ & $-1.1 \mathrm{E}-12$ & $8.2 \mathrm{E}-5$ & $2.6 \mathrm{E}-2$ & $0.0 \mathrm{E}+0$ & $6.9 \mathrm{E}-3$ \\
V4 & $5.2 \mathrm{E}-1$ & $4.9 \mathrm{E}-2$ & $6.4 \mathrm{E}-2$ & $1.3 \mathrm{E}-5$ & $-8.6 \mathrm{E}-13$ & $1.3 \mathrm{E}-2$ & $3.6 \mathrm{E}-3$ & $-1.7 \mathrm{E}-13$ & $1.1 \mathrm{E}-2$ \\
V5 & $5.0 \mathrm{E}-1$ & $3.1 \mathrm{E}-2$ & $1.2 \mathrm{E}-1$ & $3.0 \mathrm{E}-4$ & $-2.2 \mathrm{E}-12$ & $1.3 \mathrm{E}-2$ & $1.2 \mathrm{E}-2$ & $-1.1 \mathrm{E}-12$ & $1.6 \mathrm{E}-2$ \\
V6 & $6.5 \mathrm{E}-1$ & $3.7 \mathrm{E}-2$ & $2.9 \mathrm{E}-2$ & $1.8 \mathrm{E}-5$ & $-3.1 \mathrm{E}-12$ & $1.4 \mathrm{E}-3$ & $1.3 \mathrm{E}-3$ & $-2.0 \mathrm{E}-11$ & $1.6 \mathrm{E}-2$ \\
L1 & $8.0 \mathrm{E}-3$ & $9.3 \mathrm{E}-1$ & $1.7 \mathrm{E}-1$ & $-1.0 \mathrm{E}-7$ & $6.6 \mathrm{E}-5$ & $-3.9 \mathrm{E}-5$ & $-2.4 \mathrm{E}-5$ & $1.7 \mathrm{E}-3$ & $-3.2 \mathrm{E}-5$ \\
L2 & $6.3 \mathrm{E}-1$ & $3.5 \mathrm{E}-2$ & $1.6 \mathrm{E}-1$ & $5.6 \mathrm{E}-6$ & $2.1 \mathrm{E}-1$ & $2.6 \mathrm{E}-5$ & $1.4 \mathrm{E}-4$ & $7.1 \mathrm{E}-3$ & $2.3 \mathrm{E}-5$ \\
L3 & $2.3 \mathrm{E}-1$ & $1.6 \mathrm{E}-2$ & $1.1 \mathrm{E}-1$ & $2.9 \mathrm{E}-6$ & $6.6 \mathrm{E}-1$ & $3.0 \mathrm{E}-6$ & $1.1 \mathrm{E}-5$ & $7.1 \mathrm{E}-3$ & $2.5 \mathrm{E}-6$ \\
\hline
\end{tabular}

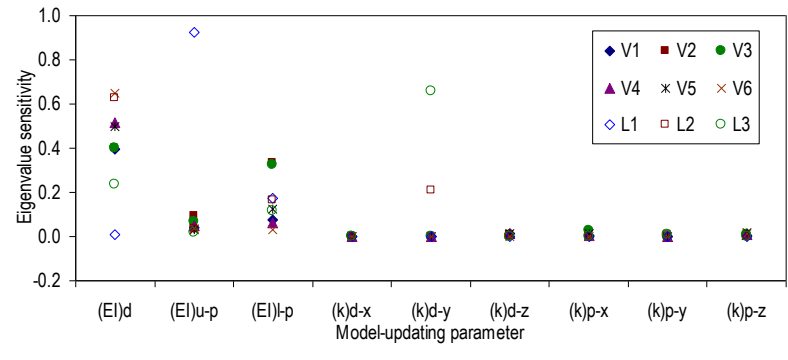

Figure 23. Eigenvalue sensitivities of model-updating parameters

From the results of sensitivity analysis, the stiffness of deck was the most sensitive parameter for both vertical and lateral modes. The stiffness of pylons was relatively sensitive parameters. Meanwhile, the stiffness of support springs were less sensitive parameters, as shown in Fig. 23. That is, those less sensitive parameters were expected to contribute less intensively on the model update. Due to the availability of the nine modes including six vertical modes and three lateral modes, one modelupdating phase was chosen in order to update the nine model-updating parameters.

\section{B. Identification of structural parameters}

After selecting the dynamic responses and structural parameters, an iterative procedure was carried out for model update by Eqs. (6) (9). Natural frequencies of the first six vertical modes and three lateral modes were used to update the FE model through twelve iterations. The system identification results are listed in Table 4 and also shown in Figs. 24 and 25. Table 4 shows natural frequencies of FE model during twelve iterations of model update. Figure 24 shows convergence errors of the natural frequencies of updated model during twelve iterations, with compared to target natural frequencies. Natural frequencies were converged within 0.0\%-4.9\% differences. Note that the maximum difference of the FE model reduced from $8.8 \%$ to $4.9 \%$ after twelve iterations. The fundamental natural frequency (i.e., mode V1) was good matching with the experimental one (i.e., $1.4 \%$ difference).

Also, the relative changes in structural parameters of FE model due to model update are shown in Fig. 25. Those fractional changes in model-updating parameters were computed with respect to the twelfth iteration as the reference. As shown in Fig. 25, the parameters have a large change in several early iterations and converge in later iterations (i.e., converge to one).

Table 4. Natural frequencies of FE model during model update

\begin{tabular}{|c|c|c|c|c|c|c|c|c|c|c|c|c|c|c|}
\hline \multirow{2}{*}{ Mode } & \multirow{2}{*}{$\begin{array}{c}\text { Initial } \\
\text { freqs. } \\
(\mathrm{Hz})\end{array}$} & \multicolumn{12}{|c|}{ Updated frequencies $(\mathrm{Hz})$ at each iteration } & \multirow{2}{*}{$\begin{array}{c}\text { Target } \\
\text { freqs. } \\
(\mathrm{Hz})\end{array}$} \\
\hline & & 1 & 2 & 3 & 4 & 5 & 6 & 7 & 8 & 9 & 10 & 11 & 12 & \\
\hline V1 & 0.466 & 0.464 & 0.463 & 0.458 & 0.456 & 0.455 & 0.453 & 0.451 & 0.450 & 0.450 & 0.450 & 0.450 & 0.450 & 0.444 \\
\hline V2 & 0.681 & 0.684 & 0.686 & 0.682 & 0.681 & 0.682 & 0.683 & 0.684 & 0.684 & 0.684 & 0.685 & 0.685 & 0.685 & 0.720 \\
\hline V3 & 1.082 & 1.083 & 1.085 & & 1.070 & 106 & & & & 20 & & & 1.027 & 1.028 \\
\hline V4 & 1.158 & 1.151 & 1.146 & 1.128 & 1.117 & 1.107 & 1.089 & 1.070 & 1.066 & 1.064 & 1.067 & 1.067 & 1.068 & 1.084 \\
\hline V5 & 1.275 & 1.266 & 1.262 & 1.239 & 1.230 & 1.223 & 1.211 & 1.199 & 1.200 & 1.202 & 1.205 & 1.206 & 1.207 & 1.171 \\
\hline V6 & 1.564 & 1.555 & 1.543 & 1.517 & 1.501 & 1.480 & 1.450 & 1.425 & 1.423 & 1.423 & 1.428 & 1.429 & 1.431 & 1.462 \\
\hline L1 & 0.443 & 0.443 & 0.454 & 0.460 & 0.462 & 0.464 & 0.464 & 0.463 & 0.458 & 0.461 & 0.457 & 0.456 & 0.455 & 0.454 \\
\hline L2 & 0.669 & 0.674 & 0.673 & 0.666 & 0.664 & 0.661 & 0.657 & 0.656 & 0.653 & 0.653 & 0.653 & 0.653 & 0.653 & 0.666 \\
\hline L3 & 1.136 & 1.167 & 1.174 & 1.169 & 1.168 & 1.168 & 1.167 & 1.166 & 1.169 & 1.169 & 1.169 & 1.169 & 1.169 & 1.169 \\
\hline
\end{tabular}


Table 5. Model-updating parameters: initial value versus updated value

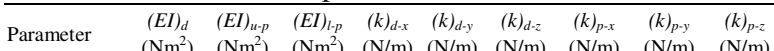
Initial value $\quad 9.9 \mathrm{E}+101.7 \mathrm{E}+115.0 \mathrm{E}+111.0 \mathrm{E}+65.0 \mathrm{E}+7 \quad 1.0 \mathrm{E}+9 \quad 1.0 \mathrm{E}+101.0 \mathrm{E}+101.0 \mathrm{E}+10$ Updated value 9.4E+10 1.8E+11 $5.5 \mathrm{E}+117.2 \mathrm{E}+66.4 \mathrm{E}+7 \quad 5.1 \mathrm{E}+8 \quad 2.5 \mathrm{E}+10 \quad 9.1 \mathrm{E}+8 \quad 8.9 \mathrm{E}+8$

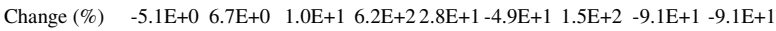

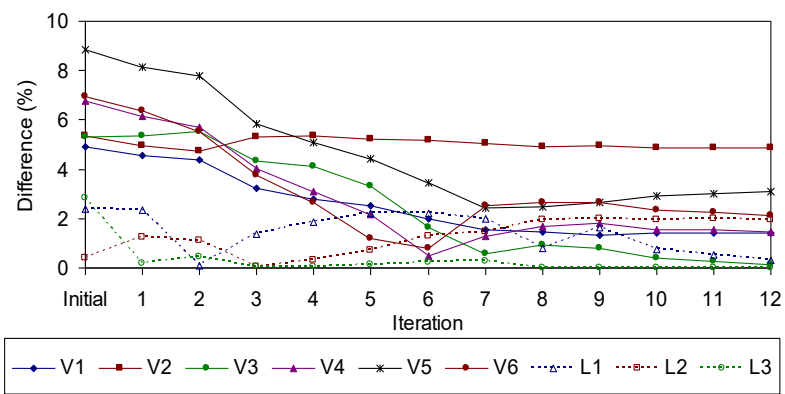

Figure 24. Convergences of natural frequencies

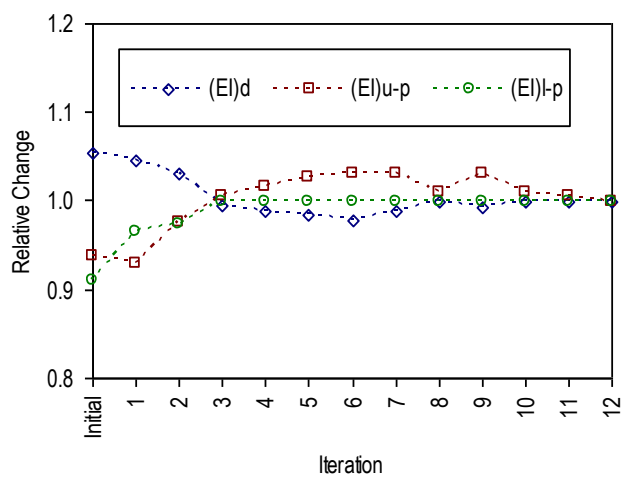

(a) Stiffness of deck and pylons

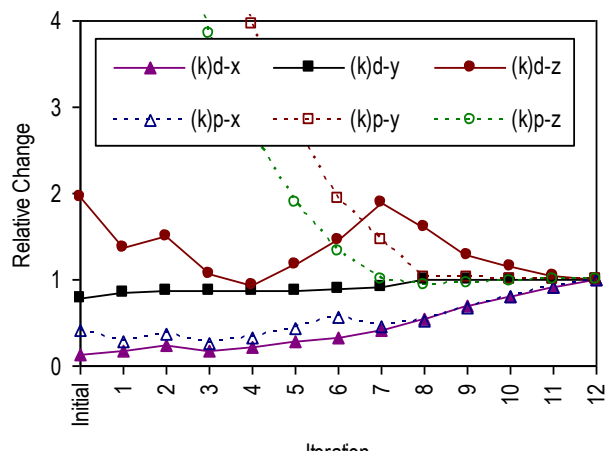

(b) Stiffness of support springs

Figure 25. Relative changes in model-updating parameters of FE model

For Hwamyung Bridge, the structural parameters are not available; meanwhile, the modal parameters can be obtained from experimental measurement. Therefore, the structural parameters of the bridge need to identify by matching the modal parameters between numerical analysis and experimental measurement. The identified structural parameters (i.e., updated parameters) are listed in Table 5. Compared to the initial parameters assigned to the initial FE model, the stiffness of deck was decreased $5.1 \%$. On the other hand, the stiffness of upper-pylons and the stiffness of lower-pylons were increased $6.7 \%$ and $10 \%$, respectively. The stiffness of support springs assumed as uncertain parameters in the initial FE model were also identified and listed in Table 5. Based on model-updating results, a numerical baseline model which represents dynamic responses of Hwamyung Bridge can be analyzed for damage assessment.

\section{SUMMARY AND CONCLUSION}

In this study, the advances in smart technologies for SHM of cable-stayed bridges were presented. First, vibration- and impedance-based SHM methods suitable for the pylon-cable-deck system in cable-stayed bridge were briefly outlined. Second, the smart sensors were described on the design of hardware components and embedded software for vibration- and impedance-based SHM. In this approach, a solar-powered energy harvesting unit was implemented for autonomous operation of the smart sensors. Finally, the applicability of smart sensor system was successfully evaluated on Hwamyung cable-stayed bridge in Korea.

The smart sensor system showed good performance on wireless communication, stand-alone operation, and solar-powered energy supply for long-term SHM operation. Vibration responses under typhoon condition were well measured and analyzed in comparison with those under normal condition. Also, vibration and impedance responses measured from the target bridge were successfully examined for the robust long-term monitoring capability of the smart sensor nodes. Cable force was well monitored by smart sensors with consideration of temperature variation. Experimental modal parameters of the target bridge were accurately extracted with compared to the numerical modal parameters. A baseline FE model representing structural parameters of the designed state of the target bridge was accurately estimated with small differences in natural frequencies by using the modal sensitivity-based structural identification method. Based on the SHM results, the target bridge has presented a healthy as-built state, equivalent to the designed state, over the monitoring period. The success of field experiment on Hwamyung Bridge demonstrates the great potential of the smart technologies for hybrid SHM of real structures.

\section{ACKNOWLEDGEMENT}

This research is funded by the Brain Korea 21 (BK21) program of Korean Government. The authors would also like to especially thank the AUN/SEED-Net sponsorship for the Regional Conference in Civil Engineering 2017.

\section{REFERENCES}

[1] S. W. Doebling, C. R. Farrar, and M. . Prime, "A summary review of vibration-based damage identification methods," Shock Vib. Dig., vol. 30, no. 2, pp. 91-105, 1998.

[2] J. T. Kim, J. H. Park, D. S. Hong, and W. . Park, "Hybrid health monitoring of prestressed concrete girder bridges by sequential vibration-impedance approaches," Hybrid Heal. Monit. Prestress. Concr. girder Bridg. by Seq. Vib. approaches, vol. 32, pp. 115-128, 2010.

[3] B. . Spencer and S. Cho, "Wireless smart sensor technology for monitoring civil infrastructure: technological developments and full-scale applications," in Proceeding of the World Congress on Advances in Structural Engineering and Mechanics (ASEM'11 Plus), 2011.

[4] Straser, E.G., and Kiremidjian, A.S. (1998), "A modular, wireless damage monitoring system for structure", 
[5] Technical Report 128, John A. Blume Earthquake Engineering Center, Stanford University, Stanford, CA

[6] Lynch J.P., Wang, W., Loh, K.J., Yi, J.H., and Yun, C.B (2006), "Performance monitoring of the Geumdang bridge using a dense network of high-resolution wireless sensors", Smart Materials and Structures, Vol. 15, pp. 1561-1575.

[7] Mascarenas, D.L., Todd, M.D., Park, G., and Farrar, C.R. (2007), "Development of an impedance-based wireless sensor node for structural health monitoring", Smart Materials and Structures, Vol. 16, pp. 2137-2145.

[8] Rice, J.A., Mechitov, K., Sim, S.H., Nagayama, T., Jang, S., Kim, R., Spencer, Jr, B.F., Agha, G., and Fujino, Y. (2010), "Flexible smart sensor framework for autonomous structural health monitoring", Smart Structures and Systems, Vol. 6, No. 56, pp. 423-438.

[9] Kim, J.T., Park, J.H., Hong, D.S., and Ho, D.D. (2011), "Hybrid acceleration-impedance sensor nodes on Imote2-platform for damage monitoring in steel girder connections", Smart Structures and Systems, Vol. 7, No. 5, pp. 393-416.

[10] Yi, J.H., and Yun, C.B. (2004), "Comparative study on modal identification methods using output-only information", Structural Engineering and Mechanics, Vol. 17, No. 3-4, pp. 445-446.
[11] Zui, H., Shinke, T., and Namita, Y. (1996), "Practical formulas for estimation of cable tension by vibration method", Journal of Structural Engineering, Vol. 122, No. 6, pp. 651-656.

[12] Stubbs, N., and Kim, J.T. (1996), "Damage localization in structures without baseline modal parameters", AIAA Journal, Vol. 34, No. 8, pp. 1644-1649.

[13] Ho, D.D., Kim, J.T., Stubbs, N., and Park, W.S. (2012), "Prestress-force estimation in PSC girder using modal parameters and system identification", Advances in Structural Engineering (Special Issue), Vol. 15, No. 6, pp. 997-1012.

[14] Jo, H., Rice, J.A., Spencer, B.F., and Nagayama, T. (2010), "Development of a high-sensitivity accelerometer board for structural health monitoring", Proceedings of the SPIE, San Diego.

[15] Miller, T.I., Spencer, B.F., Li, J., and Jo, H. (2010), "Solar energy harvesting and software enhancements for autonomous wireless smart sensor networks", NSEL Report Series, NSEL022.

[16] Ho, D.D. (2012), "Multi-scale smart sensing of vibration and impedance for structural health monitoring of cable-stayed bridge", Ph.D Dissertation, Pukyong National University, Korea. 